\title{
Do rainfalls wash out anthropogenic airborne magnetic particulates?
}

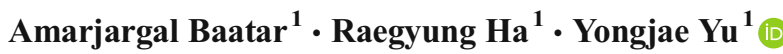

Received: 20 September 2016 / Accepted: 13 February 2017 /Published online: 1 March 2017

(C) The Author(s) 2017. This article is published with open access at Springerlink.com

\begin{abstract}
We separated dust particles from the mesh-filtered sets of rainwaters collected on rainy days with daily precipitations exceeding $10 \mathrm{~mm}$ per day. A total of 136 rainwaters (or snow during the winter season) samples collected from February 2009 to February 2013 were analyzed. In particular, 33 out of 136 rainwaters were collected during or just after the Asian dust storm (ADS) events. Values of $\mathrm{pH}$ were relatively higher during warmer seasons. During ADS events, precipitations were alkaline, possibly due to abundant supply of alkaline minerals from the deserts source area to the precipitation. Compositional analysis on particulate matter (PM) indicated that $\mathrm{Fe}$ (and $\mathrm{Al}, \mathrm{K}$, and $\mathrm{Mg}$ ) enriched the dusts collected during ADS, with respect to events than those without ADS. We found that ADS rainfall events are effective in selectively eliminating dust particles. However, high rainfall does not necessarily indicate more dilution of dusts. On microscopic examination, we observed natural soils, natural dust of pedogenesis or weathering origin, anthropogenic $\mathrm{C}-\mathrm{Fe}$-rich particles, and anthropogenic C-rich particles. Because of its small size, the stoichiometry of ADS-related, Fe-rich dust particles was inferred from the magnetic analysis. Presence of Verwey transition near 100-120 K and experimental determination of Curie points near $580{ }^{\circ} \mathrm{C}$ indicate that magnetic mineral responsible for the magnetic properties of ADS-related dusts was magnetite.
\end{abstract}

Responsible editor: Thomas D. Bucheli

Yongjae Yu

yongjaeyu@cnu.ac.kr

1 Department of Astronomy, Space Science, and Geology, Chungnam National University, Daejeon 34134, South Korea
Keywords Rainfalls $\cdot$ Asian dust storms $\cdot$ Anthropogenic pollutions $\cdot$ Precipitation $\cdot$ Particle size $\cdot$ Monthly variation . Magnetic material $\cdot$ Heavy metals

\section{Introduction}

Air pollution has acute impact on human health as the average adult, at rest, consumes over $10^{4} \mathrm{~L}$ of air in a day (Koenig 2012). Urban air pollution results both from anthropogenic and natural sources, although it is mostly caused by human activities. Anthropogenic air pollution involves emission of harmful material including black carbon, heavy metals, and sulfates into atmosphere, causing disease or even death of living organisms (Guo et al. 2004; Hsu et al. 2004; Ramana et al. 2010). In practice, particulate matter (PM) is the most hazardous pollution component widely present in the environment (Donaldson 2003). It is true that natural events including evaporation of organic material, forest fires, pollen disposal, and volcanic outgassing also contribute to the air pollution.

Asian dust storm (ADS) is often reworded as yellow dust, yellow sand, yellow wind, or China dust storms in the literature. It is produced when high-speed surface winds soar dense clouds of solid particles from the Gobi and Taklamakan deserts. Such uprising airflow generates buoyant energy to form ADS. Prevailing westerly winds spread the ADS along the stratosphere or upper troposphere. Once produced, small PM (particulates smaller than $5 \mu \mathrm{m}$ in diameters $\left(\mathrm{PM}_{5}\right)$ ) can be transported across East Asia, and the Pacific, as far away as North America (Ma et al. 2001).

ADS has effects on the global climate system by affecting the radiation budget, atmospheric chemistry, and the air quality and human health (Kim et al. 2003; Ramana et al. 2010). In addition, the worst air quality during seasonal ADS events is notorious as it is directly relevant to the cardiovascular and 
respiratory diseases (Kwon et al. 2002). Anthropogenic pollution is probably intensified as the winds pass over eastern China, which is currently the world largest sulfur dioxide emitter (e.g., Shu et al. 2000, 2001; Wang et al. 2007, 2008). In addition, increase of desertification in Asia produced ADS more frequently over the last few decades.

Quantitative estimates of past rainfall and magnetic tracing of PM are now available from high-resolution magnetic measurements on dust particles collected from ancient soils or rocks (e.g., Maher et al. 1994; Maher 2009; Liu et al. 2012). In particular, the high-resolution sensitivity, rapid measurement, and non-destructive nature of magnetic measurements make magnetic monitoring as a useful tool for detecting environmental signals associated with anthropogenic PM (e.g., Salome and Meynadier 2004; Chaparro et al. 2006; Sagnotti et al. 2006). Over the last few decades, physicochemical influence of dust particulates on rain has been explored (e.g., Ro et al. 2001; Avila et al. 1998; Seto and Hara 2006). The aim of present study is to check the wash-out effects of rainfalls on anthropogenic PM in South Korea, by relating precipitation chemistry of rainfalls and magnetic properties of PM with or without ADS.

\section{Materials and methods}

Korea is located in a downstream bottleneck of prevailing westerly winds in East Asia. The study area, Daejeon metropolitan city, is the fifth largest city of South Korea with a population over 1.5 million, located about $20 \mathrm{~km}$ away from the Sejong City (a new administrative capital of South Korea). The wet sample collector was installed on the roof of fivestory building W11-1, Chungnam National University $\left(36^{\circ}\right.$ $21^{\prime} 58.82^{\prime \prime} \mathrm{N}, 127^{\circ} 20^{\prime} 23.95^{\prime \prime}$ E) (Fig. 1).

Temporal variations of dust density in air and the amount of rainfall were officially recorded in local stations operated by Korea Meteorological Administration (KMA). A total of 136 rainwaters (or snow during the winter season) samples collected from February 2009 to February 2013 were analyzed in this study. In particular, 33 out of 136 rainwater samples were collected during or just after the ADS events, with a hope to directly compare the properties of PM before and after the ADS events. Path of air parcel can be traced using the Hybrid Single-Particle Lagrangian Integrated Trajectory (HYSPLIT) model (Draxler and Hess 1998) associated with global data assimilation system (Stein et al. 2015). The HYSPLIT model (http://ready.arl.noaa.gov/HYSPLIT.php) for $33 \mathrm{ADS}$ events were displayed for $72 \mathrm{~h}$ at altitudes of $500 \mathrm{~m}$ (Fig. 1a), $1000 \mathrm{~m}$ (Fig. 1b), and $1500 \mathrm{~m}$ (Fig. 1c).

For each rainwater sample, more than $2000 \mathrm{~mL}$ of rainwater was initially collected. On rainwater collection, values of $\mathrm{pH}$ and electrical conductivity (EC) were measured. For each $\mathrm{pH}$ measurement, the $\mathrm{pH}$ electrode was calibrated three times,
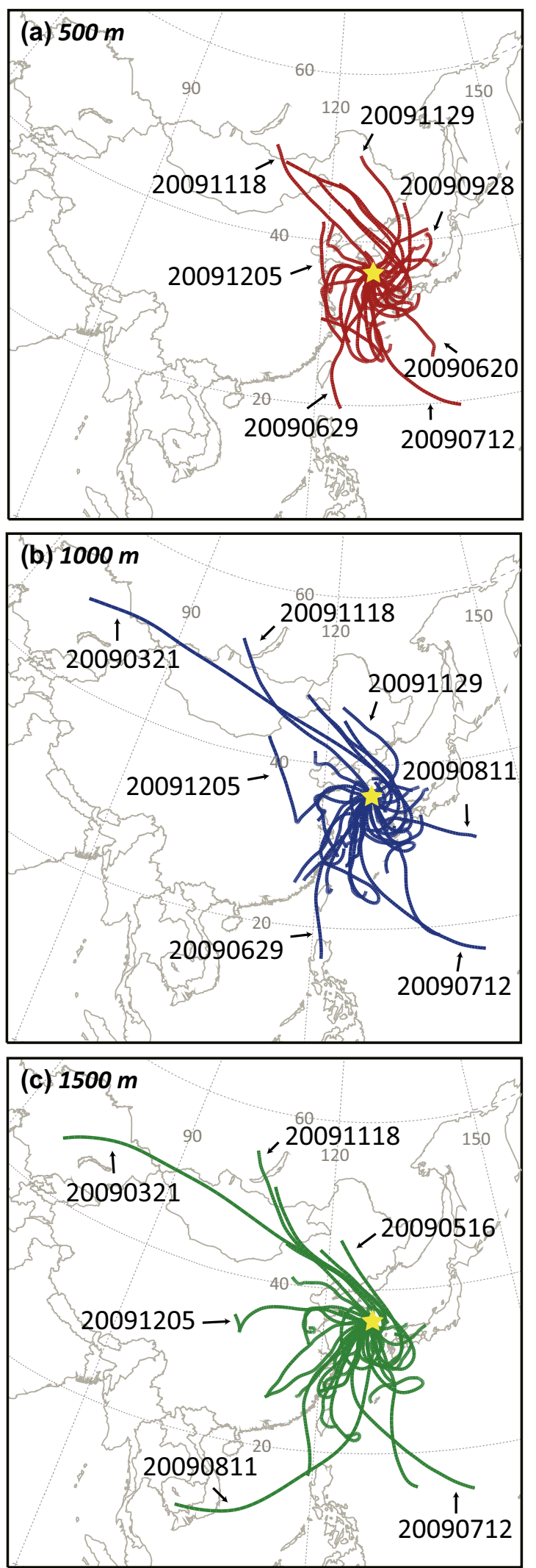

Fig. 1 Location map of study area with examples of backward trajectory using Hybrid Single-Particle Lagrangian Integrated Trajectory (HYSPLIT). Trajectories at a $500 \mathrm{~m}, \mathbf{b} 1000 \mathrm{~m}$, and c $1500 \mathrm{~m}$ above mean sea level (amsl) were traced for $72 \mathrm{~h}$ for 33 ADS events 
using buffer solutions with $\mathrm{pH}$ of $4.00,7.00$, and 10.00 , respectively. To extract solid particles from the rainfall, rainwater samples were filtered successively with six different sequentially down-sizing membrane filters with pore sizes of 5.0, 3.0, 1.0, 0.45, 0.2, and $0.1 \mu \mathrm{m}$.

Morphology and chemical composition of the dust particles extracted have been analyzed by using scanning electron microscope (SEM) (FE-SEM JSM-7000F) and electron probe X-ray microanalyzer (model JXA8800R). At first, solid particles present in membrane filters were analyzed by SEM with energy-dispersive X-ray spectroscope (EDS). On completion of SEM and EDS analyses, particles were selected in largest order for further compositional analysis for each rain-filtered $\mathrm{PM}_{5}$. A total of 1030 (103 samples $\times 10$ grains per sample) and 990 (33 samples $\times 30$ grains per sample) compositional determinations were carried out using electron probe X-ray microanalyzer (EPMA) for solid extracts from non-ADS and ADS events, respectively. The operating conditions of SEM used an accelerating voltage of $15 \mathrm{keV}$ with a sample current of 5.0 nA for energy-dispersive analysis. For quantitative EPMA analysis, we set signal collecting times for $100 \mathrm{~s}$ and background countings for $50 \mathrm{~s}$. On the basis of previous experience, we now know that dust particles often contain carbon-bearing materials (e.g., Kim et al. 2007, 2008, 2009). Hence, platinum coating rather than carbon coating was applied prior to compositional analysis.

Magnetic analysis was focused on characterization of solid particles extracted from 33 rainfall events during or just after the ADS events. For magnetic analysis, solid particles of $\mathrm{PM}_{5}$ collected from fiber filters were tightly wrapped in a nonmagnetic plastic straw. Dust particles extracted from rainfalls were subjected to stepwise isothermal remanent magnetization (IRM) acquisition up to a field of $1 \mathrm{~T}$. The peak fields were applied with an ASC Scientific IM-10 impulse magnetizer. All the magnetic experiments were measured on a JR6 spinner magnetometer (AGICO, Brno, with a noise level of $10^{-11} \mathrm{~A} \mathrm{~m}^{2}$ ). We secured enough dusts from 33 ADS-related rainfall events that are measurable on magnetic instruments with magnetic moment at least an order stronger than the noise level. Unfortunately, dusts collected from 103 non-ADSrelated raining events were magnetically too weak with magnetic moment similar to or even less than the noise level. As a quick and non-destructive technique, IRM is dependent on the magnetic mineralogy, concentration, and distribution of magnetic coercivity. IRM component analysis (https://maxunmix. shinyapps.io/MAX_UnMix final_version/) is useful in evaluating distribution of magnetic coercivity in material (Kruiver et al. 2001; Heslop et al. 2002; Egli 2003).

Because of the existing analytic limit of compositional analysis, stoichiometry of ADS-related dust particles requires confirmation from non-chemical analysis. As an alternative mineral compositional determination, continuous measurement of IRM during zero-field cooling (300-10 K) and warming $(10-300 \mathrm{~K})$ was carried out. We produced room temperature saturation isothermal remanent magnetization (SIRM) in an applied field of $1 \mathrm{~T}$, and then, the room temperature SIRM was subjected to cooling in zero field $(<0.5 \mathrm{mT})$ to $10 \mathrm{~K}$ and then warming to $300 \mathrm{~K}$, using a Quantum Design MPMS at the Institute of Geology and Geophysics, Chinese Academy of Sciences.

\section{Results}

Monthly variations of pH (Fig. 2a) and EC (Fig. 2b) are displayed in box plots, where central box represents the inter-quartile and whisker lines are extending to include the maximum and minimum. Precipitation acidity is strongly dependent on the presence of acidic and alkaline elements. Pure water $(\mathrm{PW})$ has a neutral $\mathrm{pH}$ value of 7 , and seawater $(\mathrm{SW})$ typically shows $\mathrm{pH}$ from 7.5 to 8.4 (Jenkins 1989). In a clean atmosphere, the $\mathrm{pH}$ of precipitated rainwater or snow is expected to be weakly acidic due to dissolution of carbon dioxide $\left(\mathrm{CO}_{2}\right)$ and the existence of background sulfur dioxide $\left(\mathrm{SO}_{2}\right)$ (Börner et al. 2013; Seinfeld and Pandis 2016). If the $\mathrm{CO}_{2}$-rich water $(\mathrm{CW})$ is in equilibrium with the atmosphere, the $\mathrm{pH}$ would be as low as 5.65 (Börner et al. 2013). In the present study, values of $\mathrm{pH}$ were relatively closer to $\mathrm{PW}$ over the summer season but were biased towards the value of $\mathrm{CW}$ over the winter season (Fig. 2a). In particular, the pH was highly acidic in January (Fig. 2a).

The EC reflects the amount of ionic content in a solution. For instance, pure water is far from being a good conductor with $\mathrm{EC}<10^{-2} \mu \mathrm{S} / \mathrm{cm}$. Typical ranges of EC for $\mathrm{CW}$ are 0.2 $2.0 \mu \mathrm{S} / \mathrm{cm}$, while those for rainwater or snow (RS) are 20 $100 \mu \mathrm{S} / \mathrm{cm}$ (Atkins 1947; Komabayasi and Isono 1967; Jenkins 1989). In this study, values of EC fell in an envelope of RS (Fig. 2b). It is apparent that values of EC were relatively higher in colder seasons (Fig. 2b), which is opposite the trend observed for $\mathrm{pH}$ (Fig. 2a).

Mean values of $\mathrm{pH}$ and EC from 33 samples collected during or just after the ADS events (solid symbols in Fig. 2c) were $7.23 \pm 0.68$ and $19.79 \pm 2.12 \mu \mathrm{S} / \mathrm{cm}$, while those from 103 non-ADS samples (open symbols in Fig. 2c) were $6.14 \pm 1.12$ and $37.55 \pm 2.05 \mu \mathrm{S} / \mathrm{cm}$, respectively. For comparison, occurrence of individual ADS was displayed as gray circles (Fig. 2a, b). Samples collected during or just after the ADS events tend to have higher $\mathrm{pH}$ and lower EC than those irrelevant to ADS events (Fig. 2c).

Compositional data are also presented in box plots, where central box represents the inter-quartile and whisker lines are extending to include the maximum and minimum (Fig. 3). Solid extracts from non-ADS-related rainwater (Table 1) show the abundance of elements of $\mathrm{Si}, \mathrm{Al}, \mathrm{Zn}, \mathrm{Fe}, \mathrm{Cu}, \mathrm{K}, \mathrm{Ca}, \mathrm{Na}$, $\mathrm{Mg}, \mathrm{Cl}$, and $\mathrm{S}$ in decreasing order (Fig. 3a). Similarly, solid extracts from ADS-related rainwater showed an enrichment of 
Fig. 2 a Monthly variations of $\mathrm{pH}$ in rainfalls or snow. $\mathbf{b}$ Monthly variations of EC in rainfalls or snow. c Correlation between $\mathrm{EC}$ and $\mathrm{pH}$ for rainfalls with and without Asian dust storm (ADS) events. $P W$ pure water, $S W$ seawater, $C W$ water in $\mathrm{CO}_{2}$ equilibrium with atmosphere, $R S$ rain or snow. Gray circles denote the occurrence of individual ADS (a)

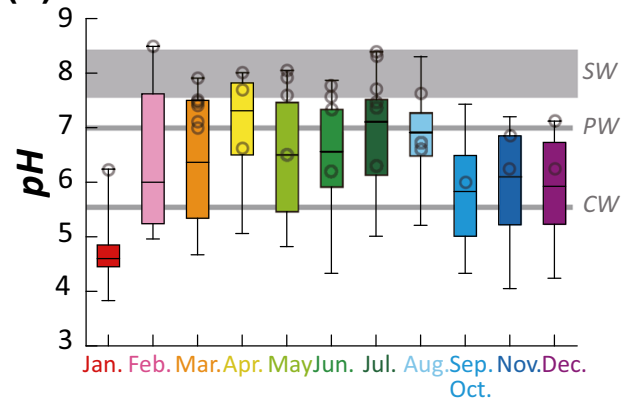

(b)
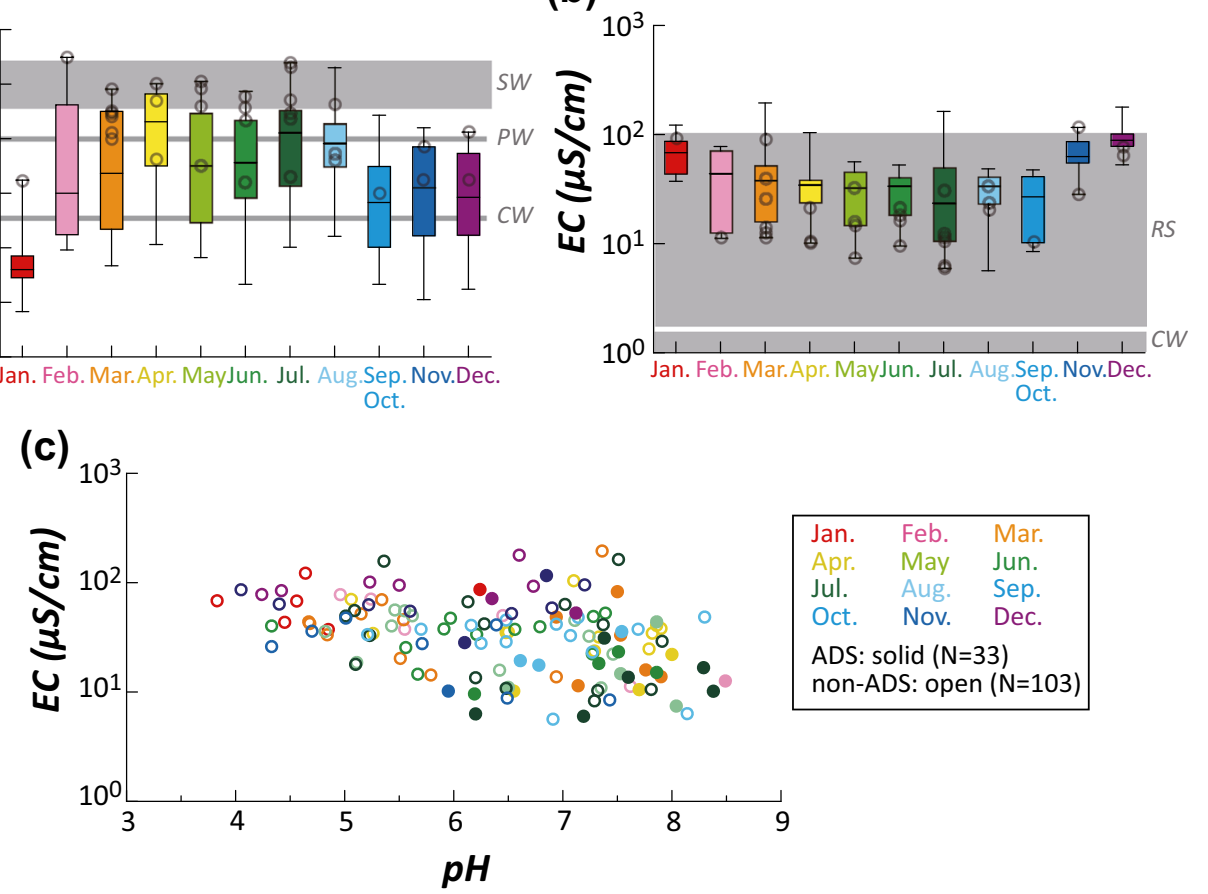

$\mathrm{Al}, \mathrm{Fe}, \mathrm{K}$, and $\mathrm{Mg}$ and a depletion of $\mathrm{Zn}$ and $\mathrm{Cu}$ (Fig. $3 \mathrm{~b}$ and Table 1).

Amount of $\mathrm{PM}_{5}$ (albeit dust densities) was plotted as a function of rainfall (Fig. 4a). For rainfalls between 10 and $15 \mathrm{~mm}$ /day (dashed squares in Fig. 4a), dust density ranges from 89 to $648 \mu \mathrm{g} / \mathrm{m}^{3}$ (Fig. 4a). With increasing rainfalls, dust density plummeted and then remained rather constant with increasing rainfalls (two dashed arrows in Fig. 4a). Such rather constant dust density in air is evident during the summer season (Fig. 4a). There is an outlier with extremely lower dust density of $32 \mu \mathrm{g} / \mathrm{m}^{3}$ recorded on August 11, 2009 (Fig. 4a).

Mass of extracted $\mathrm{PM}_{5}$ from 33 ADS-related rainfall events was compared with that predicted from the temporal variation of dust density in local station prior to raining event (Fig. 4b). If raining event is effective in diluting the dust in air, $\mathrm{PM}_{5}$ from rainfalls is in relation of $1: 1$ proportion to that from dust in air (Fig. 4b). Majorities of results are highly biased towards higher concentrations of $\mathrm{PM}_{5}$ for rainfall than those of $\mathrm{PM}_{5}$ for air. In particular, results obtained from March, April, and May are highly biased towards $\mathrm{PM}_{5}$ from rainfalls (Fig. $4 \mathrm{~b}$ ). It is therefore important to emphasize that high rainfall does not guarantee more dilution of dusts in air (Fig. 4b).

On the basis of shape and compositional analysis, solid particulates were divided into four types in order of abundance. Particles in type A were sharp edged, with average length of $10-40 \mu \mathrm{m}$ (Fig. 5). They were rich in crustal elements of $\mathrm{Si}, \mathrm{Al}, \mathrm{Fe}, \mathrm{K}, \mathrm{Na}$, and $\mathrm{Cu}$. The richest element for type A was Si. On the basis of crystal morphology and elemental composition, it is likely that type A originated from local soil which is basically weathered granite (Fig. 5).

Particles in type B were angular with average diameter of 5-30 $\mu \mathrm{m}$ (Fig. 5). They were composed of mainly Fe and O,
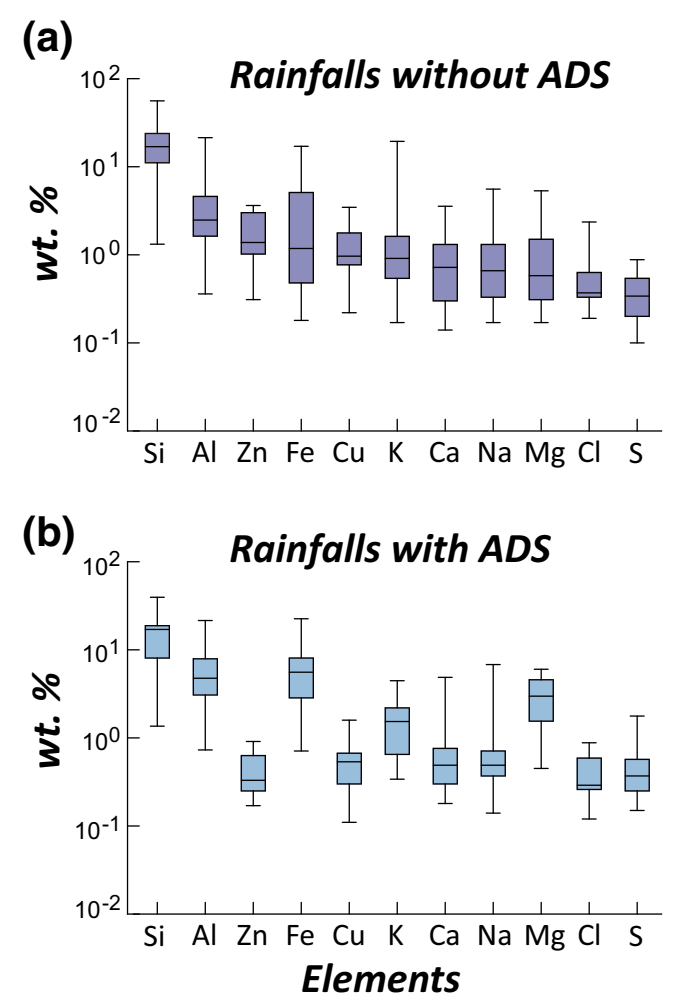

Fig. 3 Abundance of elements on rainfalls for a non-ADS events and $\mathbf{b}$ ADS events 
Table 1 Abundance of elements on rainfalls for non-ADS and ADS events in wt.\%

\begin{tabular}{|c|c|c|c|c|c|c|}
\hline & \multicolumn{3}{|c|}{ Without ADS } & \multicolumn{3}{|c|}{ With ADS } \\
\hline & Median & Maximum & Minimum & Median & Maximum & Minimum \\
\hline $\mathrm{Si}$ & 16.9 & 55.96 & 1.32 & 17.03 & 39.52 & 1.36 \\
\hline $\mathrm{Al}$ & 2.48 & 21.39 & 0.36 & 4.76 & 21.51 & 0.73 \\
\hline $\mathrm{Zn}$ & 1.38 & 3.63 & 0.31 & 0.33 & 0.91 & 0.17 \\
\hline $\mathrm{Fe}$ & 1.18 & 17.06 & 0.18 & 5.58 & 22.51 & 0.71 \\
\hline $\mathrm{Cu}$ & 0.97 & 3.46 & 0.22 & 0.54 & 1.59 & 0.11 \\
\hline K & 0.91 & 19.4 & 0.17 & 1.54 & 4.46 & 0.34 \\
\hline $\mathrm{Ca}$ & 0.72 & 3.56 & 0.14 & 0.49 & 4.87 & 0.18 \\
\hline $\mathrm{Na}$ & 0.66 & 5.57 & 0.17 & 0.49 & 6.8 & 0.14 \\
\hline $\mathrm{Mg}$ & 0.58 & 5.33 & 0.17 & 2.98 & 6.02 & 0.45 \\
\hline $\mathrm{Cl}$ & 0.37 & 2.36 & 0.19 & 0.29 & 0.88 & 0.12 \\
\hline S & 0.34 & 0.88 & 0.10 & 0.37 & 1.77 & 0.15 \\
\hline
\end{tabular}

with some contribution of crustal elements including $\mathrm{Mg}, \mathrm{Ca}$, $\mathrm{Al}, \mathrm{K}$, and $\mathrm{Na}$. These angular iron-rich oxide particles were possibly originated from natural processes, such as pedogenesis or weathering (Kim et al. 2007, 2008, 2009).

Particles in type $\mathrm{C}$ were mostly rounded or aggregate of ellipsoidal- or mushroom-shaped particulate (Fig. 5). These particles were dominated by $\mathrm{Fe}$ and $\mathrm{C}$ with minor contributions from $\mathrm{Al}, \mathrm{Ca}, \mathrm{Mg}$, and $\mathrm{Si}$. In addition, trace amount of $\mathrm{Cu}$, $\mathrm{Cr}, \mathrm{Zn}$, and $\mathrm{Pb}$ was also common. These rounded Fe-bearing particles were unlikely to represent natural minerals but were produced by fossil fuel combustion process considering their C-Fe contents and morphological characteristics (Matzka and Maher 1999).

Particles in type D were 1-10 $\mu \mathrm{m}$ in length with various morphologies including irregular and aggregate existing together (Fig. 5). They were characterized by their overwhelming carbon contents with less than a few percent contributions of copper, aluminum, and iron; they can be recognized as black carbon of combustion origin (Griffin and Goldberg 1979). It should be highlighted that black carbon has direct effects on climate system by absorbing solar radiation and heating up the atmosphere (Hansen et al. 1997; Jacobson 2001, 2012; Liu et al. 2009; Menon et al. 2002).

During stepwise acquisition of IRM, samples reach saturation near an applied field of $200 \mathrm{mT}$ (Fig. 6a, b). IRM component analysis yielded two magnetic components (Fig. 6c, d). For example, sample 20,090,321 consists of softer component $1(19.8 \pm 1.2 \mathrm{mT})$ and harder component 2 $(100.0 \pm 3.7 \mathrm{mT}$ ) (Fig. 6c). Similarly, sample 20,090,927 consists of softer component $1(38.6 \pm 0.5 \mathrm{mT})$ and harder component $2(63.4 \pm 3.7 \mathrm{mT})$ (Fig. $6 \mathrm{~d}$ ).

During cooling, SIRM decreased prominently from 100 to $120 \mathrm{~K}$, as the rate of remanence change showed two peaks at $\sim 105$ and $\sim 125 \mathrm{~K}$, respectively (Fig. 7a). During the subsequent warming, the remanence increased more rapidly at the Verwey transition (Verwey 1935), suggesting the presence of magnetite (Özdemir et al. 2002). The presence of magnetic minerals similar to magnetite in ADS is also supported by the temperature dependence of saturation magnetization (Fig. 7b). Both type C and type D PM showed virtually identical temperature dependence of saturation magnetization during heating (Fig. 7b). Observed Curie point both for type $\mathrm{C}$ and type $\mathrm{D}$ dusts were near $580{ }^{\circ} \mathrm{C}$, again confirming the presence of magnetite (Fig. 7b).

\section{Discussion}

Acid rain poses a serious environmental threat as the pollutants of acid rain can damage human health through the inhalation. The nature of rainwater in Korea appears to be alkaline (spring and summer) to weakly acidic (fall and winter) (Fig. 2a). It is likely that the alkaline nature of rainwater from March to August possibly results from the high precipitation of warmer clouds buffered by soil-derived acidic PM. On the contrary, rainwater becomes more acidic from September to February as the buffering ability of soil dust declines (Fig. 2a). Although rare, the minimum $\mathrm{pH}$ of rainwater for each month was substantially lower than that of the $\mathrm{CO}_{2}$-equilibrated value of 5.6, indicating that acidic rain deserves serious attention
Fig. 4 a Dust density in air as a function of rainfall. $\mathbf{b}$ Comparison of $\mathrm{PM}_{5}$ mass of mesh-filtered dusts from 33 ADS-related rainfall events with that from the temporal variation of dust density in local stations
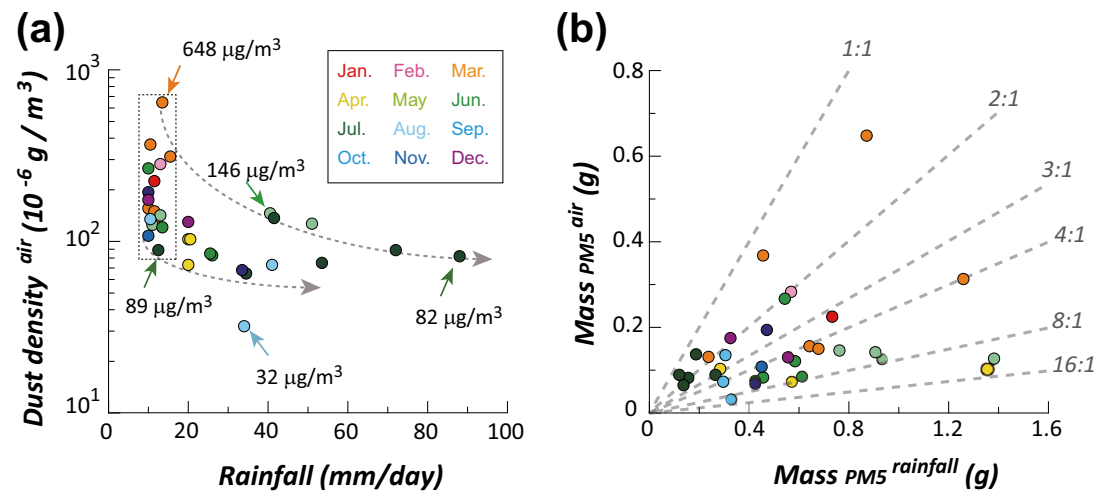

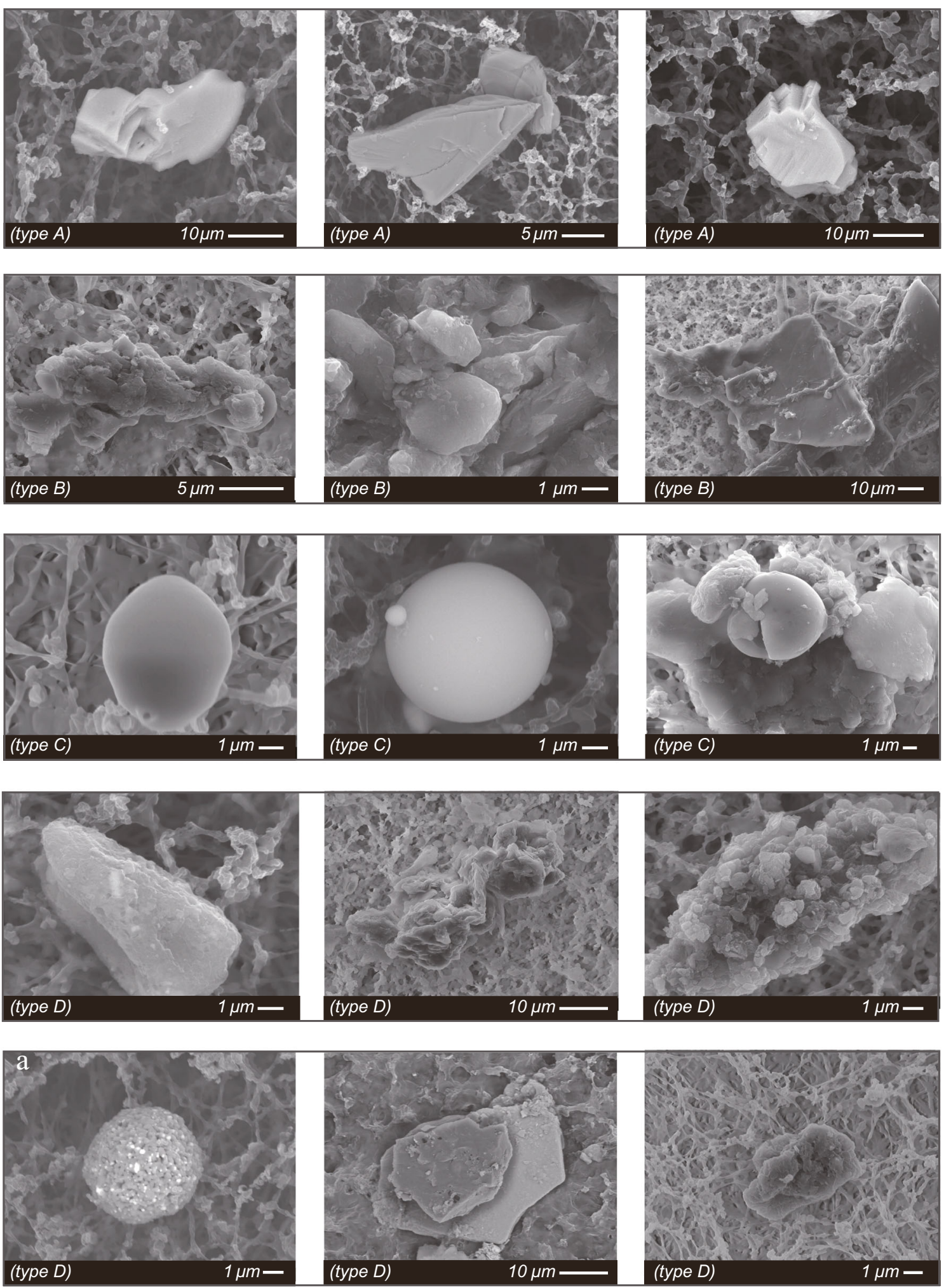

Fig. 5 Representative images of dust particles from the mesh-filtered sets of rainwaters

(Fig. 2a). During or just after the ADS events, precipitations were more alkaline (i.e., higher $\mathrm{pH}$ ) possibly due to abundant supply of alkaline minerals to the precipitation (Kang et al. 2004). It should be noted that the $\mathrm{pH}$ level of soils from the deserts source area was 7.9-9.2. As EC represents the ionic abundance but not the composition itself(Fig. 2b), $\mathrm{pH}$ is more sensitive in reflecting the chemical variations of rainwater (Fig. 2a). Individual observations of $\mathrm{pH}$ and $\mathrm{EC}$ showed a 
Fig. 6 Representative examples of isothermal remanent magnetization (IRM) acquisition. Acquisition of IRM (circles) and acquisition rate $(\Delta M / \Delta T)$ for a 2009-0321 and b 2009-0927.

IRM component analysis was provided for $\mathbf{c} 2009-0321$ and $\mathbf{d}$ 2009-0927 (https://maxunmix. shinyapps.io/MAX_UnMix final_version/). c, d Blue curves: the best fit of component 1 , purple curves: the best fit of component 2 , orange curves: the fitting sum of two components

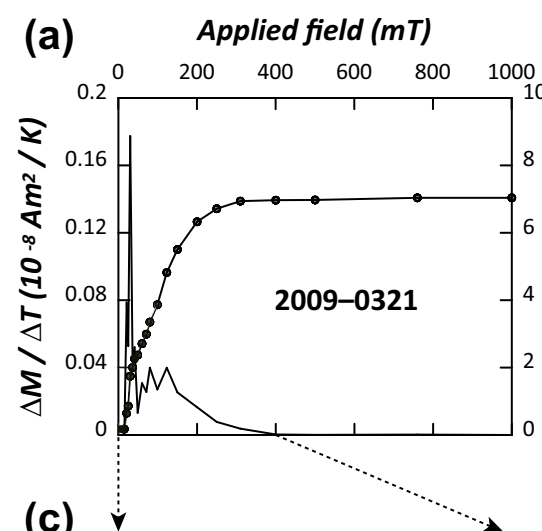

(b) Applied field ( $m$ T)

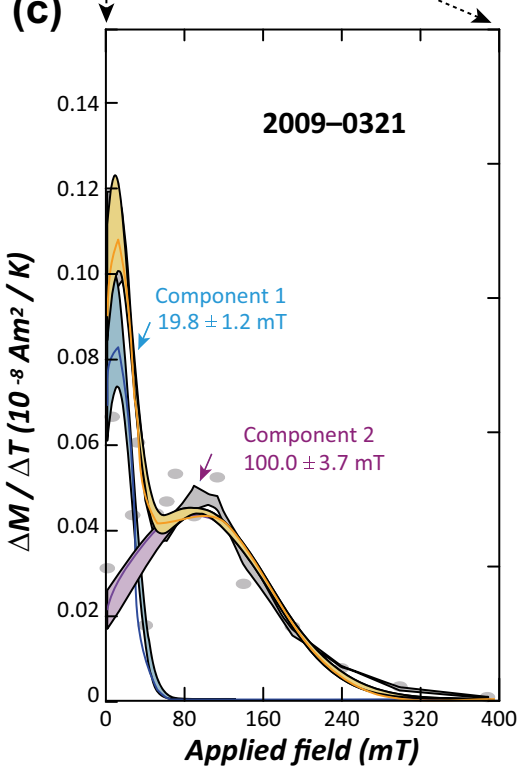

weak inverse correlation, although the results are fairly distributed (Fig. 2c). In other words, values of EC were relatively lower in warmer seasons (Fig. 2b), opposite to the trend observed for $\mathrm{pH}$ (Fig. 2a).

According to compositional analysis of rainwater with and without ADS, the enrichment of Fe content in ADS-related rainfall events is most eye-catching (Fig. 3 and Table 1). Such

(a)

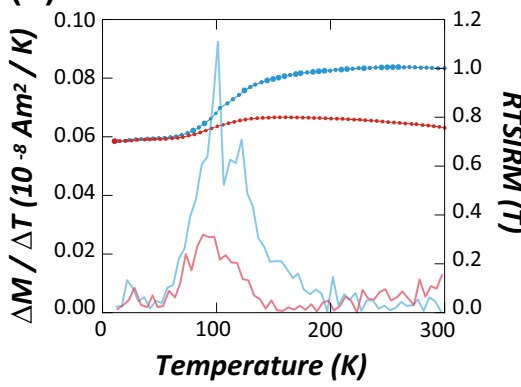

Fig. 7 a Continuous observation of room temperature saturation isothermal remanence (RT-SIRM) during zero-field cooling from 300 to $10 \mathrm{~K}$ (blue) and warming from 10 to $300 \mathrm{~K}$ (red). To induce SIRM, a field of $1 \mathrm{~T}$ was applied at $300 \mathrm{~K}$. Faint lines represent the variation rates of enhancement of $\mathrm{Fe}$ in ADS-related rainfall events matches well with the magnetic observations. Therefore, it is likely that Fe contents in air dust during ADS events increased. It has been suggested that anthropogenic process induces enhancement of hazardous elements in air, including Fe enrichment from the $\mathrm{Fe}$-smelting plant, $\mathrm{Cu}$ enrichment from vehicle traffic, and $\mathrm{Pb}$ enrichment from anthropogenic sources (Wei and (b)

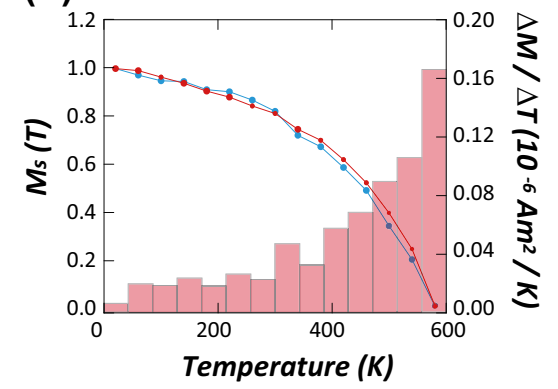

saturation isothermal remanence. $\mathbf{b}$ Temperature dependence of saturation magnetization $\left(=M_{s}\right)$ at high temperatures indicates the presence of magnetite for type $\mathrm{C}$ and type $\mathrm{D}$. Insets represent the variation rates of $M_{S}$ in histograms 
Yang 2010; Zhang et al. 2012; Lee et al. 2013). Another important observation is that $\mathrm{Zn}$ and $\mathrm{Cu}$ were efficiently diluted on rainfall events (Fig. 3).

On the basis of dust density variations with rainfall events, it is possible that the wash-out effect of rainfall was most prominent for rainfalls about $10-20 \mathrm{~mm} /$ day (Fig. 4a). Of course, it does not necessarily indicate that rainfall over 10$20 \mathrm{~mm} /$ day was less effective in diluting dust density in air. Instead, it is more likely that dust was diluted well enough during the early stage of intense rainfalls (Fig. 4b).

Four different types of $\mathrm{PM}_{5}$ were recognized in the present study (Fig. 5). They were natural soils (type A), natural dust of pedogenesis or weathering origin (type $\mathrm{B}$ ), anthropogenic $\mathrm{C}-$ Fe-rich particles (type C), and anthropogenic C-rich particles (type D). Sulfides or sulfates can be produced from the oxidation of SO originated from coal-burning and traffic emission and natural sea salt. Despite common documentations on the presence of abundant sulfides in ADS (Streets et al. 2000), magnetic techniques were sensitive in identifying dilution effect of Fe-bearing minerals only because sulfides or sulfates in rainfalls were likely to be non-magnetic (Fig. 6).

It is natural to consider that Fe-rich materials (type $\mathrm{C}$ and type D) are anthropogenic in origin. On the basis of HYSPLIT analysis, majorities of ADS passed over the industrialized area in eastern China and western Korea. However, we cannot exclude the possibility that $\mathrm{C}-\mathrm{Fe}$-bearing material of local origin of vehicle brake and tire wear might also contribute to the dust signals (Varrica et al. 2013).

Verwey transition (Verwey 1935) and Curie temperature data (Fig. 7) suggest that the main magnetic mineral in ADS dusts is likely to be magnetite. However, compositional data suggest that $\mathrm{Fe}$-rich minerals are far from being stoichiometric magnetite. Considering the carbon-related composition and their unique particle morphology, it is possible that anthropogenic processes might produce individual spherical particles or aggregates of fine-grained magnetite, whose surface is carbon coated as a result of combustion process. If so, presence of double peaks at $\sim 105$ and at $\sim 125 \mathrm{~K}$ on cooling of RT-SIRM can be interpreted as the Verwey transition of magnetite interior (possibly component 1) and that of carbon-coated shell (possible component 2). But then, it is unclear why such contrast disappeared during warming of RT-SIRM (Fig. 7a).

It is intuitively obvious that rainfall dilutes dusts in air. In the present study, we found that Fe-rich material is more effectively concentrated in rainfalls, suggesting that rainfalls are natural pollution filters for Fe-rich material. In the future, magnetic sensitivity can be used as a proxy for anthropogenic contribution of dust storms as a non-destructive and quick scientific technique. In the present study, only water-filtered solid particles of $\mathrm{PM}_{5}$ collected from fiber filters were used because the amount of dusts extracted by smaller size filters $\left(\mathrm{PM}_{3}, \mathrm{PM}_{1}, \mathrm{PM}_{0.45}, \mathrm{PM}_{0.2}, \mathrm{PM}_{0.1}\right)$ were beyond the resolution limits of magnetic instruments available. In the future, larger water tank is necessary to collect more rainfalls to characterize magnetic properties of dusts extracted by smaller-size filters. In addition, it remains technically challengeable to measure magnetic properties of air-filtered dust samples during nonADS days on short exposure.

\section{Conclusion}

This study demonstrates the following facts:

1. We analyzed a total of 136 rainwaters (or snow during the winter season) collected in Daejeon, Korea, from February 2009 to February 2013. Monthly variations of $\mathrm{pH}$ showed that rainfalls in Korea were alkaline from March to August due to high precipitation of warmer clouds buffered by soil-derived particles. On the other hand, rainfalls became weakly acidic in colder seasons as the buffering ability decreased.

2. Monthly variations of EC showed that values of EC were relatively lower in warmer seasons, opposite to the trend observed for $\mathrm{pH}$.

3. Based on the compositional analysis of rainwater with and without ADS, $\mathrm{Fe}$ is concentrated in ADS-related rainfall events. Such concentration of Fe in ADS-related rainfall events is supported from magnetic observation. We also found that rainfall events are fairly effective in selectively removing $\mathrm{Zn}$ and $\mathrm{Cu}$.

4. Dust densities were denser for rainfalls of $10-15 \mathrm{~mm} /$ day. With increasing rainfalls, dust density appears to converge towards $0.1 \mathrm{mg} / \mathrm{m}^{3}$.

5. If raining event is effective in diluting the dust in air, dust density with and without rainfalls should be proportional. However, a systematic biased towards higher values of dust density with rainfalls was observed.

6. In the present study, four different types of $\mathrm{PM}_{5}$ were recognized as natural soils (type A), natural dust of pedogenesis or weathering origin (type $\mathrm{B}$ ), anthropogenic $\mathrm{C}-$ Fe-rich particles (type $\mathrm{C}$ ), and anthropogenic $\mathrm{C}$-rich particles (type D).

Acknowledgments Hoabin Hong, Soojin Jang, Doohee Jeong, Hanul Kim, and Inho Kim provided tremendous help in collecting rain samples.

\section{Compliance with ethical standards}

Funding This work was supported by the Polar Academic Program (PD16010), Korea Polar Research Institute, 2016.

Open Access This article is distributed under the terms of the Creative Commons Attribution 4.0 International License (http:// creativecommons.org/licenses/by/4.0/), which permits unrestricted use, distribution, and reproduction in any medium, provided you give appropriate credit to the original author(s) and the source, provide a link to the Creative Commons license, and indicate if changes were made. 


\section{References}

Atkins WRG (1947) Electrical conductivity of river, rain and snow water. Nature 159:674

Avila A, Alarcon M, Queralt I (1998) The chemical composition of dust transported in red rains - its contribution to the biogeochemical cycle of a holm oak forest in Catalonia (Spain). Atmos Environ 32(2): 179-191

Börner JH, Herdegen V, Repke JU, Spitzer K (2013) The impact of $\mathrm{CO}_{2}$ on the electrical properties of water porous media-laboratory experiments with respect to carbon capture and storage. Geophys Prospect 61(suppl. 1):446-460

Chaparro MAE, Gogorza CSG, Chaparro MAE, Irurzun MA, Sinito AM (2006) Review of magnetism and heavy metal pollution studies of various environments in Argentina. Earth Planets Space 58:14111422

Donaldson K (2003) The biological effects of coarse and fine particulate matter. Occup Environ Med 60:313-314

Draxler RD, Hess GD (1998) An overview of the HYSPLIT_x modelling system for trajectories, dispersion, and deposition. Aust Meteorol Mag 47:295-308

Egli R (2003) Analysis of the field dependence of remanent magnetization curves. J Geophys Res 108:B22081. doi:10.1029/2002 JB002023

Griffin JJ, Goldberg ED (1979) Morphologies and origin of elemental carbon in the environment. Science 206:563-565

Guo J, Rahn KA, Zhuang G (2004) A mechanism for the increase of pollution elements in dust storms in Beijing. Atmos Environ 38: $855-862$

Hansen JE, Sato M, Ruedy R (1997) Radiative forcing and climate response. J Geophys Res 102(D6):6831-6864

Heslop D, Dekkers MJ, Kruiver PP, van Oorschot IHM (2002) Analysis of isothermal remanent magnetization acquisition curves using the expectation-maximization algorithm. Geophys J Int 148:58-64

Hsu SC, Liu SC, Lin CY, Hsu RT, Huang YT, Chen YW (2004) Metal compositions of $\mathrm{PM}_{10}$ and $\mathrm{PM}_{2.5}$ aerosols in Taipei during spring, 2002. Terr Atmos Ocean Sci 15(5):925-948

Jacobson MZ (2001) Strong radiative heating due to the mixing state of black carbon in atmospheric aerosols. Nature 409:695-697

Jacobson MZ (2012) Investigating cloud absorption effects: global absorption properties of black carbon, tar balls, and soil dust in clouds and aerosols. J Geophys Res 117(D6):D06205. doi:10.1029/2011 JD017218

Jenkins A (1989) Storm period hydrochemical response in an unforced Scottish catchment. Hydrologica Sciences 34(4):393-404

Kang G, Collett JL, Shin DY, Fujita SI, Kim HK (2004) Comparison of the chemical composition of precipitation on the western and eastern coasts of Korea. Water Air and Soil Pollution 151:11-34

Kim KH, Choi GH, Kang CH, Lee JH, Kim JY, Youn YH, Lee SR (2003) The chemical composition of fine and coarse particles in relation with the Asian dust events. Atmos Environ 37:753-765

Kim W, Doh SJ, Park YH, Yun ST (2007) Two-year magnetic monitoring in conjunction with geochemical and electron microscopic data of roadside dust in Seoul, Korea. Atmos Environ 41:7627-7641

Kim W, Doh SJ, Yu Y, Lee M (2008) Role of Chinese wind-blown dust in enhancing environmental pollution in metropolitan Seoul. Environ Pollut 153:333-341

Kim W, Doh SJ, Yu Y (2009) Anthropogenic contribution of magnetic particulates in urban roadside dust. Atmos Environ 43:3137-3144

Koenig JQ (2012) Chapter 3: physiology of the respiratory system. Health effects of ambient air pollution: how safe is the air we breathe? Springer Science \& Business Media,. ISBN: 1461545692

Komabayasi M, Isono K (1967) Electric conductivity of rain water in the cloud over the island of Hawaii. Tellus 19(3):408-419
Kruiver PP, Dekkers MJ, Heslop D (2001) Quantification of magnetic coercivity components by the analysis of acquisition curves of isothermal remanent magnetization. Earth Planet Sci Lett 189:269-276

Kwon JH, Cho SH, Chun Y, Lagarde F, Pershagen G (2002) Effects of the Asian dust events on daily mortality in Seoul, Korea. Environ Res 90:1-5

Lee PK, Youm SJ, Jo HY (2013) Heavy metal concentrations and contamination levels from Asian dust and identification of sources: a case study. Chemosphere 91:1018-1025

Liu Y, Sun J, Yang B (2009) The effects of black carbon and sulphate aerosols in China regions on East Asia monsoons. Tellus 61B:642656

Liu Q, Roberts A, Larrasoana JC, Banerjee SK, Guyodo Y, Tauxe L, Oldfield F (2012) Environmental magnetism: principles and applications. Rev Geophys 50:R4002. doi:10.1029/2012RG000393

Ma CJ, Kasahara M, Holler R, Kamiya T (2001) Characteristics of single particles sampled in Japan during the Asian dust-storm period. Atmos Environ 35:2707-2714

Maher BA (2009) Rain and dust: magnetic records of climate and pollution. Elements 5:229-234

Maher BA, Thompson R, Zhou LP (1994) Spatial and temporal reconstructions of changes in the Asian paleomonsoon: a new mineral magnetic approach. Earth Planet Sci Lett 125:461-471

Matzka J, Maher BA (1999) Magnetic biomonitoring of roadside tree leaves, identification of spatial and temporal variations in vehiclederived particulates. Atmos Environ 33:4565-4569

Menon S, Hansen J, Nazarenko L, Luo Y (2002) Climate effects of black carbon aerosols in China and India. Science 297:2250-2253

Özdemir Ö, Dunlop DJ, Moskowitz BM (2002) Change in remanence, coercivity and domain state at low temperature in magnetite. Earth Planet Sci Lett 194/3-4:343-358

Ramana MV, Ramanathan V, Feng Y, Yoon SC, Kim SW, Carmichael GR, Schauer JJ (2010) Warming influenced by the ratio of black carbon to sulphate and the black-carbon source. Nat Geosci 3:542545

Ro CU, Oh KJ, Kim H, Chun Y, Osan J, Hoog J, Grieken RV (2001) Chemical speciation of individual atmospheric particles using low-Z electron probe X-ray microanalysis: characterizing "Asian dust" deposited with rainwater in Seoul, Korea. Atmos Environ 35: 4995-5005

Sagnotti L, Marci P, Egli R, Mondino M (2006) Magnetic properties of atmospheric particulate matter from automatic air sampler stations in Latium (Italy): toward a definition of magnetic fingerprints for natural and anthropogenic $\mathrm{PM}_{10}$ sources. J Geophys Res 117(D6): D06205. doi:10.1029/2011JD017218

Salome AL, Meynadier L (2004) Magnetic properties of rivers sands and rocks from Martinique Island: tracers of weathering. Phys Chem Earth 29:933-945

Seinfeld JH, Pandis SN (2016) Atmospheric chemistry and physics from air pollution to climate change. Wiley, New York, p 1152

Seto S, Hara H (2006) Precipitation chemistry in western Japan: its relation to meteorological parameters. Atmos Environ 40:1538-1549

Shu J, Dearing JA, Morse AP, Yu LZ, Li CY (2000) Magnetic properties of daily sampled total suspended particulates in Shanghai. Environ Sci Technol 34:2393-2400

Shu J, Dearing JA, Morse AP, Yu LZ, Yuan N (2001) Determining the sources of atmospheric particles in Shanghai, China from magnetic and geochemical properties. Atmos Environ 35:2615-2625

Stein AF, Draxler RR, Rolph GD, Stunder BJB, Cohen MD, Ngan F (2015) NOAA's HYSPLIT atmospheric transport and dispersion modeling system. Am Meteorol Soc 12:2059-2077

Streets DG, Tsai NY, Akimoto H, Oka K (2000) Sulfur dioxide emissions in Asia in the period 1985-1997. Atmos Environ 34:4413-4424

Varrica D, Bardelli F, Dongarrà G, Tamburo E (2013) Speciation of Sb in airborne particulate matter, vehicle brake linings, and brake pad wear residues. Atmos Environ 64:18-24 
Verwey EJM (1935) The crystal structure of $\gamma \mathrm{Fe}_{2} \mathrm{O}_{3}$ and $\gamma-\mathrm{Al}_{2} \mathrm{O}_{3}$. Z Krist 91:65-69

Wang Y, Zhuang G, Tang W, Sun Y, Wang Z, An Z (2007) The evolution of chemical components of aerosols at five monitoring sites of China during dust storms. Atmos Environ 41: 1091-1106

Wang Y, Wai KW, Gao J, Liu X, Wang T, Wang W (2008) The impacts of anthropogenic emissions on the precipitation chemistry at an elevated site in north-eastern China. Atmos Environ 42:2959-2970

Wei B, Yang L (2010) A review of heavy metal contaminations in urban soils, urban road dusts and agricultural soils from China. Microchem J 94:99-107

Zhang C, Qiao Q, Appel E, Huang B (2012) Discriminating source of anthropogenic heavy metals in urban street dusts using magnetic and chemical methods. J Geochem Explor 119-120:60-75 